\title{
INTERAKTIVITAS RADIO SUARA SURABAYA: PENGGUNAAN, FUNGSI, DAN MODEL INTERAKTIVITAS
}

\author{
Budhi Widi Astuti ${ }^{1}$, Bonardo Marulitua Aritonang ${ }^{2}$ \\ Program Studi Ilmu Komunikasi \\ ${ }^{1,2}$ Fakultas Ilmu Sosial dan Ilmu Komunikasi Universitas Kristen Satya Wacana Salatiga \\ Email: ${ }^{1}$ widi.astuti@staff.uksw.edu
}

\begin{abstract}
Abstrak
Radio Suara Surabaya (SS FM) adalah lembaga penyiaran swasta yang mampu menjalankan perannya sebagai radio milik publik. Keunikan perannya diawali dengan beralihnya fungsi SS FM yang semula kontennya didominasi dengan hiburan menjadi konten informasi. Perubahan dominasi konten ini berakibat pada format siaran dua arah, dimana terdapat interaktivitas di dalamnya. Penelitian ini bertujuan mengetahui tentang interaktivitas yang terjalin antara SS FM dan pendengarnya, termasuk media yang digunakan, bentuk-bentuk interaktivitas, dan faktor terjadinya interaktivitas. Computer-Mediated Communication merupakan salah satu teori media yang digunakan sebagai pisau analisis. Melalui metode penelitian kualitatif, ditemukan bahwa dalam interaktivitas dengan pendengarnya, SS FM memiliki aturan baku yang harus ditaati bersama. Sedangkan unsur-unsur yang terdapat di dalamnya adalah partisipasi, kontrol dan keaktifan. Selain itu, media interaktivitas yang digunakan adalah telepon, media online dan media sosial. Kemudian bentuk interaktivitas yang terjadi adalah interaktivitas konten dan interaktivitas personal. Sedangkan tiga faktor yang menyebabkan pendengar berinteraksi secara aktif dengan SS FM, yaitu kebutuhan akan informasi, kebutuhan aktualisasi diri, dan kebutuhan eksistensi diri.
\end{abstract}

Kata Kunci: interaktivitas, radio, Suara Surabaya, pendengar

\begin{abstract}
Radio Suara Surabaya (SS FM) is a private broadcasting institution capable of carrying out its role as a public radio. The uniqueness of its role begins with the switch of the SS FM function which originally dominated the content with entertainment into information content. This change in the dominance of content results in a two-way broadcast format, where there is interactivity in it. This study aims to find out about the interactivity that exists between SS FM and its listeners, including the media used, the forms of interactivity, and the factors of interactivity. Computer-Mediated Communication is one of the media theories used as a knife for analysis. Through qualitative research methods, it was found that in interactivity with the listeners, SS FM has standard rules that must be adhered to together. While the elements contained in it are participation, control and activity. In addition, the interactivity media used are telephone, online media and social media. Then the form of interactivity that occurs is interactivity of content and personal interactivity. While three factors cause listeners to interact actively with SS FM, namely the need for information, the need for self-actualization, and the need for self-existence.
\end{abstract}

Keywords: interactivity, radio, Suara Surabaya, listener

\section{PENDAHULUAN}

Latar Belakang

Di era digital saat ini, kehadiran internet telah menciptakan interaktivitas antar penggunanya. Keunikan inilah yang membedakan antara komunikasi secara tradisional dan 
komunikasi yang telah dimediasi melalui internet. Penyiaran radio masa kini pun tak lepas dari penggunaan internet untuk berkomunikasi dengan pendengarnya. Mulai dari penyiaran streaming hingga partisipasi pendengar yang dilakukan berbasis online. Radio Suara Surabaya (selanjutnya disebut sebagai SS FM) merupakan salah satu lembaga penyiaran swasta yang aktif mengadopsi teknologi baru untuk memenuhi kebutuhan pendengarnya. Format siaran SS FM adalah news-interaktif, dan solutif (Hadi, 2014). News adalah fokus produksi informasi; kemudian interaktif bermakna pola komunikasi yang multi arah; dan solutif adalah berorientasi dampak siaran bermanfaat. Memaknai format siaran yang seperti ini, artinya SS FM memproduksi informasi yang tidak sekedar diterima secara pasif oleh pendengar, namun ditanggapi dan diresponi melalui aktivitas komunikasi interaktif sehingga menghasilkan solusi yang bermanfaat bagi pendengarnya. Bahkan produksi pesan tidak hanya dilakukan oleh pihak SS FM, melainkan pendengar pun dapat berpartisipasi di dalamnya. Dengan demikian, format news-interaktif dan solutif inilah yang membawa SS FM sebagai radio yang mendorong proses pemberdayaan dan demokratisasi masyarakat (B.H., Arifin, 2010: viii).

Pemilihan format siaran news-interaktif dan solutif ini memiliki perjalanan yang cukup panjang sebelumnya. Berdasarkan penelitian yang dilakukan oleh Sampoerno dkk pada tahun 2017, ditemukan bahwa SS FM telah mengalami pergeseran peran dan fungsinya sebagai lembaga penyiaran swasta menjadi seperti lembaga penyiaran publik (radio publik). Pergeseran ini nampak dari fungsinya yang semula sebagai sumber informasi bergeser menjadi fungsi pengaduan. Format awal SS FM adalah seperti koran, dimana mereka menyiarkan berbagai informasi kepada pendengarnya, namun seiring berjalannya waktu, SS FM semakin dipercaya oleh pendengarnya sebagai tempat pengaduan. Pendengar mengadu tentang berbagai hal, misalnya listrik padam, air tidak mengalir, lalu lintas macet, kecelakaan, orang hilang dan masalah publik lainnya. Ketika fungsi SS FM bergeser ke fungsi pengaduan, maka muncullah format interaksi yang baru antara SS FM dan pendengarnya. Semula, interaksi hanya berisi permintaan lagu dan salam kemudian bergeser menjadi pengaduan. Medianya pun berubah. Semula hanya melalui saluran telepon lokal, sekarang bertambah melalui internet. Hal inilah yang memunculkan dinamika interaktivitas di SS FM karena kehadiran teknologi digital yang memungkinkan terjadinya model interaktivitas yang baru. Tentu saja hal tersebut adalah wajar, sebab radio haruslah menjadi digital - radio terjebak dalam dunia analog yang berisiko menjadikannya tidak relevan, terutama bagi pendengar muda, sementara harapan pendengar terhadap interaktivitas, kualitas dan pilihan menjadi semakin meningkat (Fleming, 2010: 28).

\section{Konteks Penelitian}

Konteks penelitian ini adalah fokus terhadap interaktivitas yang terjadi antara SS FM dan pendengarnya sebagai akibat bergesernya fungsi dan peran SS FM serta akibat hadirnya teknologi komunikasi di era digitalisasi saat ini.

\section{Hasil Kajian Pustaka \\ Computer-mediated communication (CMC)}

Dalam menjalankan format siarannya yang mengandung unsur interaktif, SS FM mengadopsi konsep Computer-mediated communication (CMC), yaitu segala bentuk komunikasi yang termediasi oleh teknologi digital (Littlejohn dan Foss, 2009: 161). Studi tentang CMC, salah satunya, saat ini berkaitan dengan interaktivitas dalam berbagai bentuk yang termediasi oleh komputer, terutama penggunaan komputer untuk berkomunikasi melalui online internet. Misalnya, e-mail, chat room, bulletin board. Poin utamanya yaitu bahwa apa yang dimediasi adalah komunikasi, bukan informasi atau hiburan (Littlejohn dan 
Foss, 2009: 162). Pendiri Journal of Computer-Mediated Communication, Sheizaf Rafaeli adalah teoris kunci yang membantu kita memahami interaksi dalam CMC. Dalam artikelnya di tahun 1988, Rafaeli membedakan antara connectivity (konektivitas), reactivity (reaktivitas), dan interactivity (interaktivitas). Jaringan harus memiliki tatap muka manusia, tetapi mereka juga harus memiliki arsitektur yang memungkinkan interaktivitas terjadi. Komunikasi dua arah tidak menjamin interaktivitas, sehingga pertukaran atau aksi-reaksi harus dapat membangun hubungan. Tanpa bentuk konektivitas yang seperti ini, hubungan hanya akan menjadi sirkular saja (Littlejohn dan Foss, 2009: 162).

Saat ini istilah interaktivitas sedang dalam masa popularitasnya. Menurut Dictionary of Media and Communications, interaktivitas (interactivity) adalah "ability to participate in, or control, media products, rather than passively receive them" (Danesi, 2009: 162). Interaktivitas adalah kemampuan untuk berpartisipasi atau mengontrol produk media, bukan sekedar menerima produk media tersebut secara pasif. Artinya, dalam interaktivitas terdapat unsur partisipasi, kontrol dan keaktifan. Istilah interaktivitas digunakan terutama untuk mendeskripsikan fenomena yang ada di masyarakat dan memetakan tipologi di masyarakat, dan istilah ini tidak memiliki kecenderungan untuk memprediksi maupun untuk menguji (Bucy, 2004). Kajian mengenai interaktivitas ini telah melewati beberapa dekade. Lebih lanjut di dalam tulisan Bucy, disebutkan bahwa istilah interaktivitas ini belum secara jelas mampu dikonseptualisasikan. Salah satu peneliti yang hendak memperjelas istilah interaktivitas tersebut adalah Kiousis (Klein, 2009). Kiousis mengatakan dengan jelas bahwa teknologi komunikasi dapat menciptakan lingkungan yang termediasi, dimana para peserta komunikasi dapat berkomunikasi satu orang kepada satu orang, satu orang kepada banyak orang dan banyak orang kepada banyak orang. Proses ini kemudian dilakukan secara timbal balik. Apabila hal ini diasumsikan dalam konteks komunikasi interpersonal, maka hal tersebut merujuk pada simulasi tentang komunikasi interpersonal. Simulasi ini kemudian menumbuhkan kesadaran mereka pada sebuah telepresence. Dengan demikian, penekanan dalam pemahaman ini adalah pada penggunaan pesawat telepon.

Dalam perkembangannya, interaktivitas ini seringkali digunakan dalam analisis media online. Bucy menyatakan terdapat dua kategori interaktivitas. Pertama, adalah interaktivitas konten (content interactivity). Interaktivitas konten ini melibatkan kontrol terhadap konsumsi informasi pada seleksi dan penampilan dari konten editorial, entah itu dalam bentuk cerita, audiovisual, atau multimedia. Tidak seperti media massa tradisional, lingkungan online memberikan kita kemudahan interaksi sepenuhnya dengan medium tersebut dengan cara clicking on hyperlinks, terlibat dalam poling a survey, unduh informasi, menelepon, streaming media, mencari arsip, mengubah penyampaian informasi, dan melakukan pembelian, semuanya dilakukan tanpa komunikasi langsung dengan orang lain. StromerGalley menyebutnya sebagai interaksi media (media interaction) (Bucy, 2004), sementara McMillan (2002) menyebutnya sebagai user-to-system interaction. Tipe interaktivitas yang kedua yang mungkin muncul di lingkungan online adalah interaktivitas interpersonal (interpersonal interactivity). Tipe ini melibatkan percakapan person-to-person yang dimediasi teknologi. McMillan menyebutnya sebagai interaksi user-to-user, sementara Stromer-Galley dalam analisisnya merujuk pada interaksi antar manusia.

\section{Pendengar Radio}

Dalam interaktivitas di media radio, tentu saja kita tidak bisa lepas dari unsur pendengar. Hingga saat ini, radio dianggap sukses sebagai sebuah medium oleh karena masih ada pendengarnya. Faktor lainnya adalah daya serap, sifat lokal, medium oral dan kemampuannya untuk melibatkan komunitas dan individu-individu ke dalam proses komunikasi interaktif sosial (Girard, 2003: 8). Program-program yang memuat isu lokal 
sangat digemari oleh pendengar. Mereka dapat berinteraksi dan saling memberikan informasi dan solusi bagi kelangsungan hidup mereka. Konsep tentang pendengar radio mengalami perubahan dari waktu ke waktu. Hal ini berkaitan dengan kemajuan teknologi informasi dan komunikasi. Di tahun 1980-an, Bordewijk dan Kaam membuat konsep tentang audiens berdasarkan kekuatan distribusi antara produser konten dan pengguna konten yang termediasi oleh tiga tipe media, yaitu classic transmission media (audiens radio dan televisi), consultation media (audiens media cetak), dan conversational media (Littlejohn dan Foss, 2009: 63). Namun, seiring berkembangnya teknologi komunikasi, konvergensi serta meningkatnya "mediatization" dalam segala aspek kehidupan moderen, Henry Jenkins memandang bahwa audiens dan masyarakat tidak lagi menjadi audiens yang pasif (Littlejohn dan Foss, 2009: 64). Oleh karenanya, peneliti menggunakan konsep audiens sebagai berikut: a group of people being addressed by and paying attention to a communication message that someone is producing and intending for them to perceive, experience, and respond to in one way or another (Littlejohn dan Foss, 2009: 64). Dalam penelitian ini, audiens yang dimaksud adalah pendengar yang menerima pesan komunikasi yang diproduksi oleh SS FM. Setelah menerima pesan komunikasi tersebut, mereka merespon dengan berbagai cara. Artinya, terjadi komunikasi dua arah antara SS FM dan pendengar tersebut.

\section{Tujuan Penelitian}

Melihat keberhasilan SS FM dalam menggunakan teknologi internet untuk berkomunikasi dengan pendengarnya ini, maka diperlukan penelitian yang lebih mendalam tentang bagaimana interaktivitas yang terjadi antara SS FM dan pendengarnya. Dengan demikian, tujuan dari penelitian ini adalah mengetahui interaktivitas yang dibangun oleh SS FM dengan pendengarnya, termasuk media yang digunakan, bentuk-bentuk interaktivitas yang dibangun, dan faktor terjadinya interaktivitas.

\section{METODE PENELITIAN}

Penelitian ini menggunakan pendekatan kualitatif, yaitu metode-metode untuk mengeksplorasi dan memahami makna yang —oleh sejumlah individu atau sekelompok orang - dianggap berasal dari masalah sosial atau kemanusiaan (Creswell, 2012: 4-5). Proses penelitian kualitatif terdiri dari upaya mengajukan pertanyaan-pertanyaan dan prosedurprosedur, mengumpulkan data yang spesifik dari para partisipan, menganalisis data secara induktif mulai dari tema-tema yang khusus ke tema-tema umum, dan menafsirkan makna data. Jenis penelitian ini sangat berguna untuk menjelaskan interaktivitas yang dibangun antara SS FM dengan pendengarnya, sehingga peneliti juga melibatkan metode penelitian studi kasus (case study). Menurut Smith (1978), kasus adalah suatu "sistem yang terbatas" ( $a$ bounded system) (Denzin dan Lincoln, 2009: 300). Akan tetapi menurut Stake (1988), keterbingkaian (boundness) dan pola-pola perilaku sistem adalah faktor kunci dalam memahami sebuah kasus.

Unit observasi adalah semacam unit data yang dapat dikumpulkan (Ihalauw, 2005). Dalam penelitian ini unit pengamatannya adalah SS FM, termasuk di dalamnya adalah orang yang terlibat langsung dalam interaktivitas dengan pendengar dan media interaktivitas yang digunakan. Sedangkan unit analisis adalah unit di mana kesimpulan akan diberlakukan (Ihalauw, 2005). Sehingga unit analisisnya adalah interaktivitas antara SS FM dan pendengarnya, termasuk di dalamnya adalah media yang digunakan, bentuk-bentuk interaktivitas, dan faktor terjadinya interaktivitas.

Data yang diperlukan dalam penelitian ini adalah data primer dan sekunder. Data primer dikumpulkan dengan cara sebagai berikut: 1) Wawancara mendalam dengan informan kunci, yaitu: a) Errol Jonathans (CEO Suara Surabaya Media); b) Iman 
Dwihartanto (Manajer Siar SS FM); dan c) Eddy (Manajer New Media SS FM). 2) Observasi/pengamatan terhadap media-media interaktif yang digunakan. Sedangkan data sekunder diperoleh dari SS FM website, facebook, twitter, dan literatur terkait. Setelah data dikumpulkan, peneliti menganalisis data tersebut dengan mengikuti tahapan James Spradley yang dikenal sebagai Developmental Penelitian Urutan, yaitu: 1) Putuskan informan; 2) Wawancara dengan informan; 3) Membuat catatan; 4) Mengajukan pertanyaan deskriptif; 5) Hasil dari wawancara; 6) Menganalisis hasil dari wawancara; dan terakhir, membuat analisis domain.

\section{HASIL DAN PEMBAHASAN \\ Perjalanan Perubahan Format Interaksi Siaran SS FM}

SS FM merupakan lembaga penyiaran swasta yang berdiri sejak tahun 1983. Visi SS FM adalah menjadi "sumber pemberdayaan dan kegiatan demokratisasi masyarakat, melalui usaha kegiatan media massa, yang mengikuti perkembangan teknologi komunikasi dan telekomunikasi". Untuk mencapai visi tersebut, maka SS FM memiliki misi sebagai: a) Perusahaan media massa yang dituntut berkembang dengan mengandalkan kemajuan teknologi komunikasi dan telekomunikasi; b) Sentra informasi tentang Surabaya dan Jawa Timur; c) Menyelenggarakan berbagai kegiatan pemberdayaan dan proses demokratisasi masyarakat; dan d) Sumber kehidupan dan kesejahteraan seluruh unsur karyawan yang bekerja untuk kemajuan bersama.

Pada awal perintisannya, tepatnya di tahun 1983, SS FM mulai menjalankan misinya menyelenggarakan kegiatan pemberdayaan. Pada saat itu, SS FM ingin membuat siaran radio yang berbeda dengan radio lainnya dimana pada saat itu banyak siaran yang hanya berisi hiburan berupa sandiwara atau request. Maka tercetuslah ide membuat siaran radio yang bermuatan jurnalistik seperti 'koran', sehingga kemudian mereka mengusung format radio journalism yang mengudara menggunakan teknologi terestrial atau teknologi yang dikatakan sebagai konvensional. Di era tersebut, interaktivitas yang dibangun masih sebatas memenuhi permintaan pendengar untuk diputarkan lagu dan berkirim salam kepada pendengar yang lain. Topik pembicaraan antara penyiar dan pendengar pun sebatas topik yang umum. SS FM hanya sekedar menjalankan fungsinya sebagai radio hiburan dan informasi bagi pendengarnya. Informasi yang disampaikan kepada pendengar adalah sebatas satu arah, tidak membutuhkan feedback dari pendengar.

Di tahun 1989, muncullah ide untuk membuat format siarannya menjadi interaktif meskipun pada saat itu belum menggunakan telepon sebagai perangkat komunikasi antara penyiar dan pendengarnya. Hal ini dilandasi oleh keinginan untuk mengedukasi pendengar melalui interaktif. Selain itu, format siaran radio journalism dirasakan sebagai peluang pada saat itu karena lembaga penyiaran publik Radio Republik Indonesia dianggap tidak dapat mengakomodir berita-berita tentang peristiwa yang terjadi di daerah lokal Surabaya. Meskipun pada saat itu, masyarakat belum terbiasa mendengarkan radio siaran swasta yang menyiarkan berita dan berbasis format jurnalistik. Setelah berbagai persiapan dirasa cukup, seperti sistemnya, sumber daya manusianya, dan organisasinya, maka ide untuk merombak format siarannya menjadi citizen journalism baru terealisasi di tahun 1994. Dimana, kegiatan siaran interaktivitasnya sudah didukung dengan teknologi komunikasi melalui telepon seluler. Di era tersebut, SS FM melibatkan pendengarnya untuk berkontribusi dalam memproduksi konten berita. Peristiwa apapun yang terjadi di sekitar pendengar, maka pendengar memiliki kesempatan untuk melaporkannya kepada SS FM. Topik-topik berita yang disampaikan oleh pendengar biasanya adalah peristiwa kecelakaan, bencana alam, perampokan/penjambretan, dan topik menarik lainnya yang unik. 
Kemudian di tahun 1999 SS FM melakukan konvergensi internet dan mengusung format new journalism. Di tahun ini dikembangkanlah portal berita suarasurabaya.net yang sangat mendukung bidang jurnalistiknya. Lalu di tahun 2013 hingga saat ini SS FM mengusung format new new journalism dengan memperluas area konvergensi yang tidak terbatas dengan internet saja, melainkan media sosial. Bicara tentang format siaran dan format interaktivitas SS FM, maka kita harus kembali mengingat bahwa motto siaran SS FM adalah news, interaktif, solutif. Artinya, SS FM mengusung format news dimana terdapat unsur jurnalistik yang sangat kuat, yang dikemas dengan cara interaktif dengan pendengarnya. Pendengar memiliki kebebasan untuk memproduksi pesan berita untuk disampaikan kepada SS FM. Harapannya, berita-berita yang disampaikan, baik yang diproduksi oleh SS FM maupun kontribusi dari pendengar dapat menjadi solusi yang terbaik bagi masalah-masalah pendengar secara keseluruhan.

\section{Media Interaktivitas di SS FM}

Interaktivitas yang terjalin antara SS FM dan pendengar terjadi melalui beberapa media, yaitu: pertama, telepon di nomor (031) 99000000; kedua, short message service (SMS) di nomor 08553010055; ketiga, media sosial di akun Facebook e100 dan akun Twitter@e100ss. Selain itu, interaktivitas juga terjalin melalui surat elektronik di redaksi@suarasurabaya.net. Di masing-masing media tersebut, interaktivitas yang terjadi sangatlah spesifik dan berbeda satu sama lain. Melalui telepon misalnya. Di sana pendengar tidak langsung berbicara dengan penyiar karena harus melalui gatekeeper yang bertugas. Jika berinteraksi melalui SMS, maka model interaksinya bisa dikatakan telah menggunakan teknologi CMC. Mengapa? Sebab saat ini telah dikembangkan software SMS yang terintegrasi dengan software siaran radio yang diakses melalui komputer. Media yang ketiga adalah melalui media sosial baik Facebook maupun Twitter. Interaktivitas melalui akun media sosial inilah yang dimaksudkan oleh CMC. Dimana, kedua belah pihak dapat melakukan komunikasi interpersonal namun dapat diakses dan dibaca/dilihat oleh banyak orang seperti karakteristik media massa. Hal ini terjadi karena $C M C$ merupakan perpanjangan dari komunikasi interpersonal yang dapat diakses secara massa.

\section{Interaktivitas yang Dibangun oleh SS FM}

Jika melihat perjalanan perubahan format siaran SS FM sejak tahun 1983, maka di tahun 1999, komunikasi yang dibangun antara penyiar dan pendengar adalah komunikasi yang termediasi oleh teknologi digital (computer-mediated communication/CMC) terutama melalui online internet. Menurut Nellis, computer-mediated communication mampu memperluas spektrum dari komunikasi interpersonal ke komunikasi massa tanpa mengabaikan fungsi komunikasi massa tradisional, yaitu: fungsi informasi, eksplanasi, hiburan dan transmisi budaya, dimana $C M C$ digunakan untuk interaksi sosial (Baldwin, Perry, Moffitt, 2004: 246).

Menurut Dictionary of Media and Communications, interaktivitas (interactivity) adalah "ability to participate in, or control, media products, rather than passively receive them" (Danesi, 2009: 162). Interaktivitas adalah kemampuan untuk berpartisipasi atau mengontrol produk media, bukan sekedar menerima produk media tersebut secara pasif. Artinya, dalam interaktivitas terdapat unsur partisipasi, kontrol dan keaktifan. Jika mengacu pada makna interaktivitas yang dikemukakan oleh Kiousis (Klein, 2009), maka di tahun 1994 adalah cikal bakal dimana interaksi timbal balik antara pendengar dan penyiar mulai tercipta dikarenakan pada tahun tersebut SS FM mulai menggunakan teknologi komunikasi yaitu telepon seluler untuk menciptakan lingkungan yang termediasi yang mendukung format siaran citizen journalism. Selanjutnya pada tahun 1999, SS FM melakukan 
konvergensi dengan internet untuk mendukung interaktivitas dengan pendengarnya, dan dilanjutkan di tahun 2013 dimana media sosial juga dipilih sebagai wujud konvergensi dengan internet.

Dalam interaktivitas yang dibangun, terdapat unsur-unsur yang harus terkandung di dalamnya, yaitu: partisipasi, kontrol dan keaktifan. Pertama, partisipasi. Bicara tentang partisipasi, kita bisa melihatnya dari sisi pendengar dan narasumber. Dari sisi pendengar bisa dilihat saat awal pendirian SS FM. Di tahun 1983, interaksi yang terjadi bersifat satu arah. Partisipasi pendengar berupa request lagu dan berkirim salam. Konten yang dibicarakan sudah pasti lebih banyak tentang hiburan. Pendengar SS juga menyukai konten informasi meskipun porsinya masih kecil karena konten musik lebih dominan pada saat itu. Namun, justru dengan memberikan konten informasi ini membuat pendengar SS FM merasakan perbedaannya dibandingkan radio lain. Dan hal ini membuat pendengar terbiasa dengan konten informasi, sehingga ketika pada waktunya SS FM memulai proses interaksi maka pendengar tidak kaget dan tidak perlu disosialisasi bahwa SS FM mengusung konten jurnalistik.

Di tahun 1994, SS FM telah menetapkan format siarannya menjadi citizen journalism dengan didukung oleh perangkat komunikasi berupa telepon seluler. Di era tersebut, SS FM mencoba mencari celah yang dapat dilakukan seperti yang disampaikan oleh Errol Jonathans berikut ini:

Nah dari sana kita mencari celah apa yang bisa kita lakukan. Mainkan semua info-info lokal lalu mengedukasi masyarakat lewat produk ini. Lalu muncul masyarakat yang mulai dalam tanda kutip setengahnya kompalin setengahnya mengusulkan. Jadi pada dua tahun pertama saya hanya memasukkan data apa data-data kota Surabaya, kita bikinkan naskah dibacakan secara oral oleh penyiar. Lama-lama pendengar bilang anda tidak bisakah mencari informasi yang happening bukan data tok. Oh berarti harus liputan, ya sudah oke, mencoba liputan tapi kan masih sangat primitive jaman itu, habis dari kantor ya ngetik dulu. Baru kemudian kita kasih script ke penyiar, pergi lagi, kita hunting. Belum ada HP belum ada apa-apa." (Errol Jonathans, wawancara, 2 Juni 2017)

Awalnya, partisipasi pendengar hanya sekedar melaporkan peristiwa yang terjadi di sekitarnya. Namun, hal ini berkembang menjadi pendengar menyampaikan opini sehingga SS FM merasa perlu menghadirkan narasumber supaya opini pendengar dapat terarah dengan baik. Yang menarik dalam praktek citizen journalism di sini adalah pendengar tidak saja menyampaikan peristiwa yang terjadi di sekitar mereka, tetapi juga menyampaikan opini mereka terhadap peristiwa tersebut. Bahkan dikatakan oleh Errol, kadang laporan yang disampaikan oleh pendengar lebih bagus daripada laporan yang disampaikan oleh reporter SS FM. Hal ini dikarenakan pendengar memiliki suara yang bagus, cara berpikir yang sangat terstruktur, dan tuturannya bagus. Kemudian, ketika pendengar membutuhkan solusi atas masalah atau peristiwa yang terjadi maka SS FM merasa bahwa mereka tidak bisa hanya menjadi 'keranjang sampah aduan' pendengar, oleh karenanya disinilah partisipasi narasumber dibutuhkan dalam interaktivitas antara SS FM dan pendengar:

"Nah ketika kemudian mulai terjadi proses dia (pendengar) butuh solusi lalu SS berpikir karena satu titik SS bisa menjadi keranjang sampah kalau kita nggak bisa menyelesaikan problem-problem orang itu. Lalu kita mencari narasumber. Awalnya cuma begitu jadi pendengar laporan lalu kita coba kroscek ke narasumber kita sampaikan lalu masuk ke tahapan narasumber ngomong 
langsung sampai ke tahapan kita ngomong langsung di udara. Terjadi dialog antara penelepon dengan narasumber. Dan ketika kemudian kita berhasil untuk mendekati ke seluruh pemangku kepentingan publik untuk mau bicara di SS, di situlah booming-nya." (Errol Jonathans, wawancara, 2 Juni 2017)

Interaksi antara SS FM dan pendengar terjalin pertama kali melalui petugas gate keeper. Aksesnya adalah melalui pintu telepon di nomor (031) 99000000; short message service (SMS) di nomor 08553010055; dan media sosial di akun Facebook e100 atau akun Twitter @e100ss. Ketika pendengar terhubung dengan petugas gate keeper, maka percakapan yang terjadi tidak disiarkan secara langsung (on air). Kemudian, pada tahapan pendengar telah terhubung dengan penyiar maka otomatis dialog terjadi antara pendengar dengan penyiar dan disiarkan secara langsung (on air). Dalam tahapan ini, penyiar memiliki kebebasan untuk berinteraksi dengan pendengar dan atau membaca pesan singkat SMS atau membaca "postingan" di media sosial.

Unsur yang kedua adalah kontrol. Dalam interaksi antara pendengar dan penyiar, maka fungsi kontrol dilakukan oleh petugas gate keeper yang mengatur lalu lintas informasi dan interaksi. Petugas gate keeper menjadi akses masuk satu-satunya menuju siaran on air SS FM. Setiap petugas gate keeper bertugas melayani telepon yang masuk dari pendengar di nomor (031) 99000000. Selain itu, mereka juga memantau pesan yang masuk melalui SMS dan memantau media sosial Facebook dan Twitter. Dari setiap informasi yang masuk melalui telepon, SMS atau media sosial tersebut, petugas gate keeper melakukan pendataan, pencatatan, penyaringan dan kemudian menyajikannya secara lugas, singkat dan tutur. Mengapa harus demikian? Sebab medium radio memiliki karakteristik auditif dimana pesan yang disampaikan adalah untuk didengar, sehingga informasi yang diucapkan oleh penyiar haruslah padat berisi, tidak bertele-tele, dan menggunakan bahasa sehari-hari yang mudah ditangkap oleh telinga pendengar.

Dalam proses interaksinya, menurut Manajer Siar SS FM Iman Dwihartanto, maka fungsi kontrol juga dilakukan dengan cara menyusun standard operasional procedure (SOP). Rohnya adalah bahwa informasi yang masuk dari berbagai media harus memiliki nilai manfaat untuk pendengar lainnya, baik melalui media telepon, SMS, maupun media sosial. Alur interaksi melalui telepon adalah pada saat petugas gate keeper menerima telepon, maka petugas gate keeper mencatat identitas penelepon, menanyakan ulang nomor telepon, nama dan alamat. Hal ini dimaksudkan sebagai bentuk konfirmasi data yang sudah ada di data induk pendengar, sekaligus sebagai cara untuk memperbaharui data pendengar SS FM untuk mengantisipasi perubahan data alamat, nomor telepon, pekerjaan, dan lain sebagainya. Setelah itu, petugas gate keeper menampung informasi yang disampaikan oleh pendengar di pendataan informasi yang terbagi dalam informasi lalu lintas, informasi layanan publik, dan informasi lain-lain. Jika proses pendataan ini selesai, maka petugas gate keeper akan memutuskan apakah pendengar yang menelepon tersebut akan diberikan pilihan siaran langsung (on air) atau cukup didata kemudian penyiar yang akan membacakan informasi tersebut seperti yang disampaikan oleh Errol Jonathans berikut ini:

"Prinsipnya kita meyakini bahwa interkatif itu tidak boleh langsung on air harus ditapis dulu harus di-screening dulu, makanya kita punya konsep screening adalah ada tiga kemungkinan, jadi yang pertama untuk informasi masuk ada kriteria untuk lolos siaran langsung, ada yang otomatis tidak lolos, ada kriteria juga repot kan tenaga harus ada klarifikssi sehingga kita pending dulu, jangan diinfokan dulu. Dengan dua kemungkinan lolos siaran atau tidak. Nah itu ada patokannya yang pertama news value-nya, kalau news value-nya menarik 
berarti lolos tapi setelah itu kita punya tools berikutnya yaitu news judgement, judgement kita itu apa. Apakah news value yang kita dapatkan ini bagus untuk disiarkan atau tidak. Yang kita pikirkan adalah dampak karena bisa saja dampaknya tinggi tapi tidak bagus kalau kita on air-kan malah misalkan bukan redam malah memperkeruh sehingga tools ini yang kita pakai." (Errol Jonathans, wawancara, 2 Juni 2017)

SOP ini juga berlaku bagi pendengar yang berinteraksi melalui SMS atau media sosial. Petugas gate keeper akan memantau SMS yang masuk dan "postingan" di media sosial milik SS FM. Hanya saja, di media interaksi ini tidak ada pilihan untuk siaran langsung sebab penyiarlah yang akan membacakan informasi yang disampaikan oleh pendengar melalui SMS atau media sosial tersebut. Proses screening ini berguna karena SS FM memiliki prinsip bahwa mereka tidak perlu menjadi yang pertama karena bagi mereka tidak ada gunanya menjadi yang pertama tetapi setelah itu mereka melakukan banyak ralat informasi yang disampaikan. Bagi SS FM, ralat justru mengganggu kredibilitas informasi sehingga menjadi tidak akurat.

Selain SOP dalam penerimaan informasi dari pendengar, ada hal lain yang harus diperhatikan oleh petugas gate keeper dan pendengar, yaitu berkaitan dengan penggunaan istilah. Oleh karena SS FM konten siarannya lebih banyak tentang informasi lalu lintas, maka ketika ada pendengar yang menyampaikan informasi tentang keadaan lalu lintas, mereka diminta supaya tidak menggunakan istilah 'macet', 'padat merayap', 'lambat' dan sebagainya. Hal ini dikhawatirkan dapat menimbulkan salah persepsi, karena kondisi kemacetan bagi warga Jakarta akan berbeda dengan Surabaya. Selain istilah, SS FM juga membuat sistem partisipasi pendengar yaitu pendengar diharuskan untuk melaporkan ke kantor layanan pemerintah terlebih dahulu sebelum melapor ke SS FM. Jika laporannya tidak ditanggapi oleh kantor layanan pemerintah maka pendengar boleh melaporkan melalui SS FM. Hal ini dilakukan karena SS FM tidak ingin menjadi media yang mengadili atau menghakimi, melainkan media yang memfasilitasi. Sehingga unsur solutif dari siaran SS FM dapat tercapai.

Unsur yang ketiga dari interaktivitas adalah keaktifan. Dalam interaktivitas, keaktifan pendengar merupakan hal yang tak terhindarkan. Dari data sekunder yang diperoleh dari SS FM menunjukkan gambaran keaktifan pendengar, yaitu:

\section{a. Pendengar yang aktif berinteraksi melalui saluran telepon}

Di bawah ini terdapat grafik yang menunjukkan bahwa pada tahun 2015, jumlah ratarata penelepon yang masuk adalah 976. Kemudian di tahun 2016, jumlahnya meningkat menjadi 1.273 .

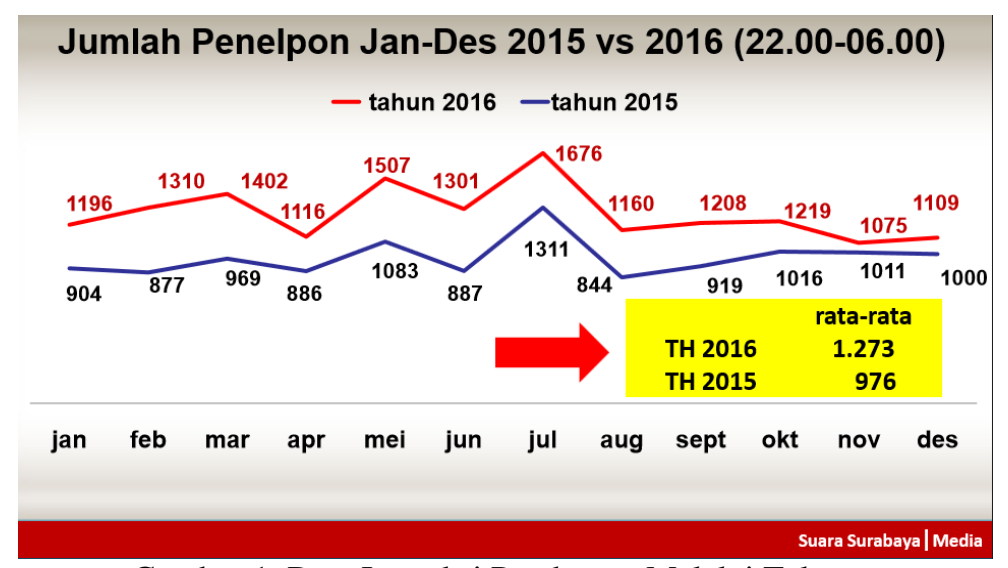

Gambar 1. Data Interaksi Pendengar Melalui Telepon

(Sumber: data sekunder SS FM, 2 Juni 2017) 
Dari data ini diketahui bahwa terdapat peningkatan keaktifan pendengar SS FM dalam berinteraksi dan menyampaikan berbagai informasi.

\section{b. Pendengar yang berinteraksi secara aktif melalui media sosial}

Selain melalui saluran telepon, pendengar juga aktif berpartisipasi melalui media sosial Facebook dan Twitter. Dari data sekunder yang diperoleh dari SS FM menunjukkan bahwa pendengar yang berinteraksi secara aktif melalui Facebook e100 adalah sebagai berikut:

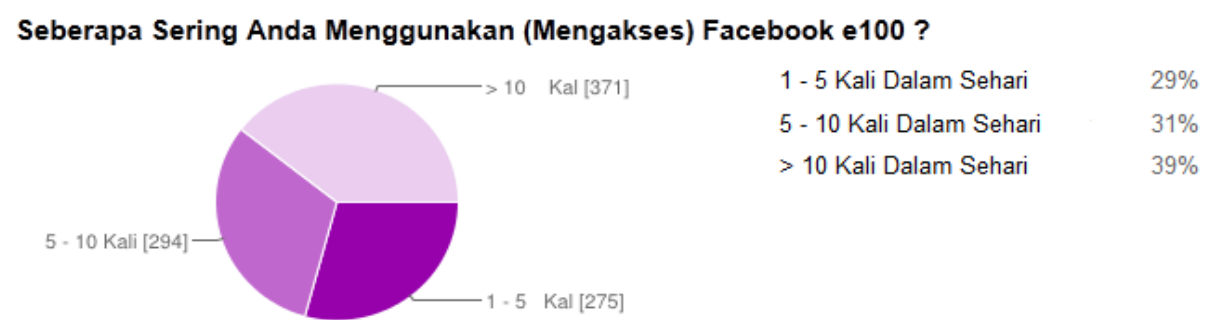

Gambar 2. Data Frekuensi Interaksi Pendengar Melalui Facebook e100 (Sumber: data sekunder SS FM, 2 Juni 2017)

Pertama, frekuensi mengakses sebanyak 1-5 kali dalam sehari sudah dianggap sebagai pengguna aktif. Kedua, tujuan mereka mengakses jika diurutkan dari yang paling banyak adalah untuk mencari informasi tentang lalu lintas, sosial/masyarakat, pemerintahan/politik, ekonomis bisnis, olahraga, mencari teman baru, memberi informasi ke sesama pengguna, dan tujuan lainnya.

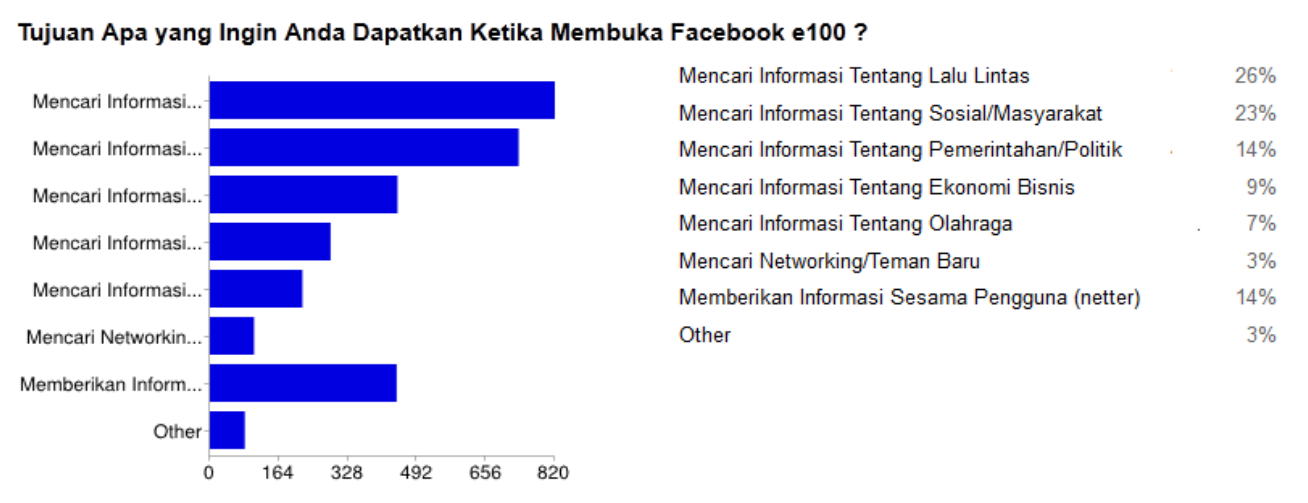

Gambar 3. Data Tujuan Interaksi Pendengar Melalui Facebook e100 (Sumber: data sekunder SS FM, 2 Juni 2017)

Ketiga, interaksi pendengar melalui media sosial Twitter @e100ss menunjukkan bahwa frekuensi mengaksesnya tidak jauh berbeda dengan media sosial Facebook e100, yaitu sebanyak 1-5 kali dalam sehari yang sudah bisa dianggap sebagai pengguna aktif. Sedangkan tujuan mereka mengakses jika diurutkan dari yang paling banyak adalah untuk mencari informasi tentang lalu lintas, berikutnya tentang sosial/masyarakat, kemudian pemerintahan/politik, ekonomis bisnis, olahraga, mencari networking atau teman baru, memberi informasi ke sesama pengguna (netter), dan tujuan lainnya. Dibandingkan dengan pengguna Facebook, maka jumlah pendengar yang mengakses Twitter@e100ss lebih banyak meskipun selisihnya tidak terlalu signifikan. 
Seberapa sering anda mengakses Twitter @e100ss?

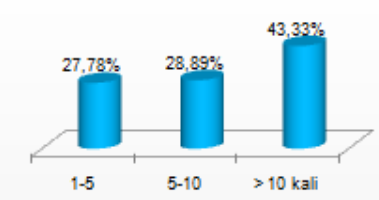

Tujuan anda mengakses Twitter @e100ss?

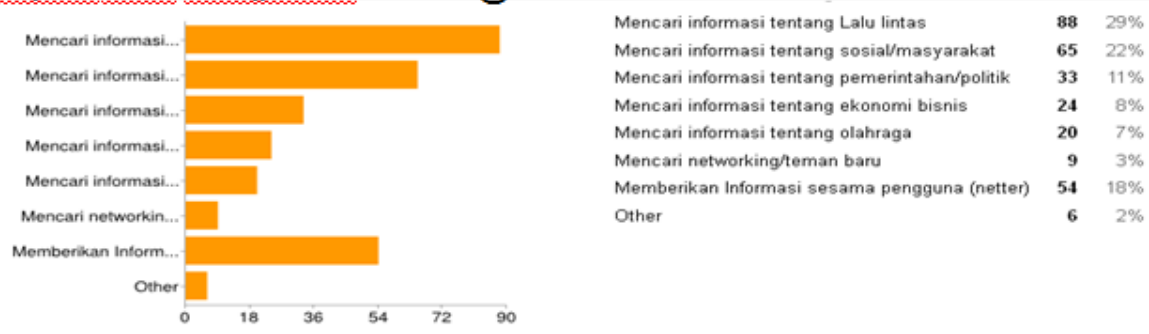

Gambar 4. Data Interaksi Pendengar Melalui Twitter@e100ss

(Sumber: data sekunder SS FM, 2 Juni 2017)

\section{Bentuk Interaktivitas di SS FM}

Bucy (2004) menyusun dua kategori interaktivitas, yaitu interaktivitas konten (content interactivity) atau media interaction dan interaktivitas interpersonal (interpersonal interactiviy). Pertama, dalam interaktivitas konten/media, maka bentuk interaktivitasnya adalah: di sisi pendengar, mereka berinteraksi dengan cara mengonsumsi informasiinformasi yang diunggah oleh SS FM di akun media sosial SS FM. Pendengar juga mengakses program audiovisual atau multimedia berupa konten-konten berita/peristiwa baik yang sifatnya periodik ataupun on demand. Selain itu, pendengar juga melakukan clicking on hyperlinks, unduh informasi, streaming media, mencari arsip, atau mengubah penyampaian informasi. Sedangkan di sisi penyiar atau petugas gate keeper, mereka dapat mengunggah informasi dan mengunduh pesan dari pendengar. Dalam perkembangannya, interaktivitas konten ini mengalami perubahan. Awalnya konten yang diunduh berupa hiburan lagu dan informasi yang terbatas pada data semata, selanjutnya seiring berjalannya waktu, kontennya menjadi beragam. Mulai dari layanan publik, info lalu lintas, orang hilang, sampai kepada kritik dan masukan tentang jalannya pemerintahan dan perkembangan kota.

Kedua, dalam interaktivitas interpersonal (interpersonal interactivity) maka bentuk interaktivitasnya adalah: menggunakan media komunikasi telepon dimana percakapan di telepon ini melibatkan person-to-person yang dimediasi teknologi komunikasi. Dalam hal ini, pendengar berinteraksi dengan petugas gate keeper dan (atau) dengan penyiar melalui telepon seluler.

\section{Pendengar Radio}

Konsep tentang pendengar radio mengalami perubahan dari waktu ke waktu, termasuk akibat dari kemajuan teknologi informasi dan komunikasi. Henry Jenkins memandang bahwa audiens dan masyarakat tidak lagi menjadi audiens yang pasif (Littlejohn dan Foss, 2009: 64). Menurutnya, audiens adalah sekelompok orang yang disasar oleh komunikator dan yang menaruh perhatian terhadap pesan yang diproduksi secara sengaja untuk mereka. Dalam penelitian ini, yang dimaksud dengan sekelompok orang tersebut adalah pendengar yang dengan maksud tertentu menaruh perhatian kepada pesan komunikasi yang diproduksi oleh SS FM. Pesan komunikasi tersebut disalurkan melalui siaran radio dan unggahan informasi di media sosial. Berbicara tentang pendengar SS FM, ada hal unik yang ditemukan yaitu pada awal mulanya interaksi SS FM dengan pendengarnya, yaitu menyangkut partisipasi dalam meminta lagu dan berkirim salam. Selanjutnya bertambah menjadi 
permintaan informasi (data) tentang pemerintahan kota Surabaya. Kemudian berubah lagi menjadi informasi yang beragam jenisnya, ditambah dengan laporan dari pendengar. Di sini, pendengar yang semula hanya sebagai konsumen pasif saja telah beralih menjadi produsen juga, terutama produsen pesan. Ketika pendengar mulai beralih menjadi produsen pesan inilah mulai muncul karakter-karakter pendengar yang pada akhirnya memunculkan tipologi pendengar SS FM. Misalnya, seperti yang disampaikan oleh Errol Jonathans:

"Ada satu pendengar yang namanya Pak Agustinus, begitu isunya tentang otomotif, jam berapa pun dia muncul. Karena dia ahli tentang itu. Mulai dari kecelakaan, mulai dari rem blong, misal gitu. Mogok di jalan tol gara-gara ini atau rem macet pasti dia akan ngomong. Jadi akhirnya orang akan menandai pas dimana Agustinus muncul. Termasuk juga pelanggaran lalu lintas, dia paling anti. Pasti dia nongol akan marah di udara. Nah, kita punya banyak tipetipe semacam ini yang akhirnya mereka punya identitas masing-masing”. (Errol Jonathans, wawancara, 2 Juni 2017)

\section{Faktor-faktor Terjadinya Interaktivitas}

Berbicara tentang keaktifan pendengar dalam berinteraksi dengan SS FM, maka faktorfaktor terjadinya interaktivitas adalah: Pertama, kebutuhan pendengar akan berbagai informasi yang penting bagi mereka. Di sini mereka bertindak sebagai konsumen pasif yang mendengarkan SS FM untuk memenuhi kebutuhan mereka. Kedua, kebutuhan pendengar untuk mengaktualisasikan diri. Di sini mereka bertindak sebagai konsumen aktif yang tidak hanya mengonsumsi pesan, tetapi juga memproduksi pesan. Tindakan memproduksi pesan ini merupakan tindakan aktualisasi diri yang di era saat ini merupakan sebuah hal yang wajar. Ketiga, ketika pendengar aktif ini mengaktualisasikan diri dan diapresiasi, maka tentunya pendengar akan melakukannya berulang-ulang kali lagi. Hal ini dilakukan sebagai upaya mempertahankan eksistensi diri mereka sebagi pendengar SS FM. Artinya, mereka akan terus mencari informasi di sekitarnya untuk dibagikan, akan terus belajar untuk melaporkannya dengan baik, dan dilandasi dengan kepedulian terhadap orang lain. Di titik inilah peneliti menganggap bahwa visi SS FM sebagai sumber pemberdayaan dan kegiatan demokratisasi masyarakat telah berhasil.

\section{SIMPULAN}

Pergeseran peran dan fungsi SS FM yang semula adalah fungsi informasi menjadi fungsi pengaduan, menyebabkan pola interaksi antara SS FM dan pendengarnya berubah pula. Di era teknologi digital saat ini, SS FM mampu mengadopsi dan beradaptasi terhadapnya dengan menerapkan format siaran news-interaktif dan solutif. Format siaran seperti inilah yang juga mengubah model interaktivitas SS FM dengan pendengarnya. Dalam membangun interaksinya dengan pendengar, SS FM menerapkan peraturan-peraturan yang harus disepakati bersama dengan pendengar supaya informasi yang disiarkan akurat dan terpercaya serta membawa manfaat yang positif bagi pendengar sesuai motto SS FM, yaitu news-interaktif-solutif. Media interaktivitas yang digunakan adalah saluran telepon lokal, SMS, dan media online, seperti website, email, dan media sosial Facebook serta Twitter. Bentuk-bentuk interaktivitas yang terjadi dikategorikan dalam interaktivitas konten dan interaktivitas interpersonal. Di sisi pendengar, mereka sangat aktif dalam berpartisipasi sekaligus melakukan kontrol. Faktor-faktor terjadinya interaktivitas dengan melibatkan pendengar adalah karena adanya kebutuhan akan informasi, kebutuhan akan aktualisasi diri, dan kebutuhan akan eksistensi diri pendengar, dimana mereka terus belajar bermanfaat bagi pendengar lain melalui informasi-informasi yang disampaikan oleh pendengar tersebut.. 
Disinilah letak keberhasilan SS FM dalam visinya menjadi media pemberdayaan dan demokratisasi masyarakat.

\section{REFERENSI}

Baldwin, J.R., Perry, S., \& Moffit, M.An. (2004). Communication Theories for Everyday Life. Boston: Pearson Education, Inc.

BH, Arifin. (2010). Suara Surabaya Bukan Radio. Surabaya: Suara Surabaya.

Bucy, E. (2004). Interactivity in Society: Towards a Theory of an Elusive Concept. Paper presented at Conference Papers - International Communication Association.

Creswell, John W. (2012). Research Design. Pendekatan Kualitatif, Kuantitatif, dan Mixed. (Terj). Yogyakarta: Pustaka Pelajar.

Danesi, Marcel. (2009). Dictionary of Media and Communication. Armonk, New York London, England: M. E. Sharpe, Inc.

Denzin, N.K., \& Lincoln, Y.S. (2009). Handbook of Qualitative Research (Terj). Yogyakarta: Pustaka Pelajar.

Facebook Suara Surabaya E100ss. Tersedia dari: https://web.facebook.com/Suara-SurabayaE100ss-824960250922538/

Fleming, Carole. (2010). The Radio Handbook $3^{\text {rd }}$ Edition. New York: Routledge.

Girard, Bruce. (2003). Radio and the Internet: Mixing Media to Bridge the Divide. In Girard, B., The One to Watch Radio, New ICTs and Interactivity (pp. 2-19). Rome: The Friedrich Ebert Foundation (FES) Geneva Office and The Communication for Development Group Research, Extension and Trainig Division Sustainable Development Department Food and Agriculture Organization of The United Nations.

Hadi, Ido Prijana. (2014). Penyiaran Interaktif dan Kepentingan Publik. Makalah disampaikan di Konferensi Nasional Komunikasi ISKI, Lombok.

Ihalauw, J.O.I. (2000). Bangunan Teori. Salatiga: Fakultas Ekonomi Universitas Kristen Satya Wacana.

Klein, B. (2009). Contrasting Interactivities: BBC Radio Message Boards and Listener Participation. Radio Journal: International Studies in Broadcast \& Audio Media, 7 (1): 11-26. doi://doi.org/10.1386/rajo.7.1.11/1.

Littlejohn, S.W., \& Foss, K.A. (2009). Encyclopedia of Communication Theory. California, London, New Delhi, Singapore: SAGE Publications, Inc.

Sampoerno., Sari, D.K., \& Herwandito, Seto. (2018). Pergeseran Peran dan Fungsi Radio Suara Surabaya Dari Radio Informasi Menjadi Radio Pengaduan. Jurnal Riset Komunikasi JURKOM, 1 (2), 01-13.

Twitter SS FM (@e100ss). Tersedia dari: http://twitter.com/e100ss.

\section{Wawancara:}

Dwihartanto, Iman. (26 Juni 2017).Manajer Siar SS FM.

Prastyo, Eddy. (2 Juni 2017). Manajer New Media SS FM.

Jonathans, Errol. (2 Juni 2017). CEO Suara Surabaya Media. 